\title{
Using Business Intelligence in IT Governance Decision Making
}

\author{
Arisa Shollo \\ Howitzvej 60, 2000 Frederiksberg, Denmark \\ Tel.: +45 27965833 \\ as.inf@cbs.dk
}

\begin{abstract}
Business Intelligence' (BI) has been widely used to describe the process of gathering, analyzing and transforming large amounts of data into information useful for decision making. This paper examines BI from a decisionmaker's perspective in an IT governance context through a case study of a large Scandinavian financial institution. The key findings indicate that BI is primarily used to inform structured operational decisions and as an instrument for dialogue in unstructured strategic decisions. Our study shows how 'hard facts' provided by $\mathrm{BI}$ are used as a foundation for opening a dialogue and as a supporting instrument to make arguments seem more convincing during decision-making discussions. We also found that standard performance reporting is used more for operational decision making, whereas predictive analytics are utilized primarily in strategic decision making. These results can assist managers looking to improve their operational and strategic decision-making processes by indicating the appropriate type of BI for each type of decision.
\end{abstract}

Keywords: Business Intelligence, decision making, case study, strategic decisions, predictive analytics.

\section{Introduction}

The importance of intelligence in decision making is recognized from ancient times (Tzu, 2006). People have developed processes, techniques and tools for collecting and analyzing intelligence to support decision making, especially during times of war (Kinsinger, 2007). Despite the considerable amount of research already conducted, decision making still remains one of the biggest challenges. The issues of decision making and computerized decisions have attracted the attention of academics and practitioners since the use of computers in organizational settings began. In the 1960s operations analysis was seen as the solution. Later, decision support was coupled to the use of computers, leading to decision support systems (DSS) (Sprague, 1980) and executive support systems (ESS) (Rockart \& De Long, 1988). After data warehousing (Inmon, 2005; Kimball \& Ross, 2002) and on-line analytical processing (OLAP) (Chaudhuri \& Dayal, 1997; Gray et al., 1996) began to broaden the realm of decision support systems in the 1990s, many organizations realized the importance of business intelligence (BI) and sought to leverage it in their work (Golfarelli et al., 2004; Wixom \& Watson, 2010). 
The concept of BI has acquired wide recognition in the business world over the last two decades. Although the term 'business intelligence' has been in use since 1800, (Google Ngram Viewer, 2011), it was used in scientific context for the first time in an article by Hans Peter Luhn, an IBM researcher. In the article, Luhn (1958) described an "automatic method to provide current awareness services to scientists and engineers" who needed help to cope with the growth of the scientific and technical literature. However, it was only in the 1990s when Howard Dresner, (Dekkers et al., 2007), popularized the term BI, that it was widely adopted to convey the idea that the collected information in a business' IT systems could be exploited by the business itself to extract new insights. Today, the term is used to describe all decision support applications, processes and technologies (Shollo \& Kautz, 2010; Wixom \& Watson, 2010).

Over the last two decades, both industry and academia have been focusing on developing and adopting BI technologies to provide intelligence and insights to decision-makers. On one side, organizations have built data warehouses, acquired BI tools, supported acceptance by end users and applied the information to make business decisions. On the other side, academics have been refining the concept of BI along with its associated development processes and best practices. Many organizations have succeeded in transforming raw data into information, actionable insights or knowledge. According to Wixom and Watson (2010), BI has moved from being a peripheral contributor to being a prerequisite for organizational success. However, the outputs of BI - information, actionable insight or knowledge - do not by themselves guarantee its use by decision-makers.

In this paper, we examine how BI is used in decision making from a decisionmaker's perspective. We conducted an extensive and in-depth literature review on the subject along with an empirical study in a financial organization to explore the use of $\mathrm{BI}$ in a decision-making environment. This study is part of a larger project in which we are investigating how we can use BI in IT governance and specifically in the IT project prioritization process.

The remainder of the paper is structured as follows. The next section presents previous work on the topic and describes the research gap. In section three we describe the methodology used to conduct the empirical study. Section four presents the results of the study and in section five we discuss the findings of the research and indicate future research directions.

\section{Background}

From a first look at the literature (Davenport \& Prusak, 1998) one understands that BI is related to strategic management and performance management. Looking at BI from a decision-maker's perspective, we investigated the current state of BI in relation to strategic management, performance management and decision making. We conducted a literature review with a focus on how managers use BI, for what purposes and with what effects on performance and strategies in an organization. For an extensive review read Shollo \& Kautz (2010).

The literature review revealed a gap in the research related to the role of decision making within BI. According to Arnott and Pervan (2008) and Yi-Ming and Liang-Cheng 
(2007), most of the studies of BI have focused on design, development and application of BI tools, neglecting the use of information and knowledge. Thus, there is a substantial amount of literature on how to gather and store raw business-related data. This literature includes studies of structured and unstructured data as well as internal and external data. These studies are combined with literature on developing and employing required technologies, such as data warehouses and document warehouses (Baars \& Kemper, 2008; Inmon, 2005; Kimball \& Ross, 2002).

There are fewer studies the analysis and transformation of data into information and information into knowledge. The focus in these studies is on methods (Golfarelli et al., 2004; Yi-Ming \& Liang-Cheng, 2007), techniques (Blumberg and Atre 2003; Baars \& Kemper, 2008; Chung et al., 2005; Negash, 2004) and technologies, such as OLAP and data mining, that facilitate the transformation of raw data into information and knowledge. Despite the fact that there is a considerable body of literature on technology support, researchers have focused mainly on technology from a problemcentric perspective, overlooking the decision-maker's perspective.

The critical research gap, however, lies in the fact that there are almost no studies, with the exception of a few (Davenport, 2010), which address decision making based on business intelligence. We argue this represents an oxymoron: while there is a consensus among the authors of all reviewed articles that BI supports decision making, none of them couple the development or use of information with the decision-making process itself. The literature on BI thus does not cover how BI addresses the needs of the decision-making process. Moreover, no studies were found that focus on how the intelligence provided is used in decision making or what processes are in place to ensure the use of intelligence in the decision-making process. One reason for this could be that BI is not a well established field and "current research is largely focused on technology and getting the data right" (Arnott \& Pervan, 2008), leading companies to focus only on those aspects when making decisions (Presthus et al., 2010; Davenport et al., 2001).

We agree with the contention of Martinsons (1994) and Davenport (2010) that it is not enough to analyze data, provide information and use knowledge. Organizations must look specifically into decision processes in order to deliver useful information to the decision-makers and for those decision-makers to act upon the information and knowledge obtained. Intelligence is only produced through action (making decisions). As Fuld (2003) states, "intelligence is an asset only if it is used". Unfortunately, in many cases, the produced information is not used, is unsuited for decision-making purposes or is ambiguous and interpreted differently across different contexts (Davenport, 2010).

The product of $\mathrm{BI}$, among other properties, must match the decision-making environment in which it is used (Clark et al. 2007). However, recent studies suggest that many organizations do not fully understand the link between their BI and the decision-making environment they use it in (Clark et al., 2007; Hostmann et al., 2007; Davenport, 2010).

In the decision-making literature, decision-making environments have been classified according to decision types. A distinction is made between structured and unstructured decisions or, as introduced by Simon (1977), between programmed and nonprogrammed decisions. Simon stated: "Decisions are programmed to the extent that they are repetitive and routine, to the extent that a definite procedure has been 
worked out for handling them so that they don't have to be treated from scratch each time they occur" (p. 46). On the other hand, decisions are nonprogrammed "to the extent that they are novel, unstructured and unusually consequential" (Simon, 2007, p. 46). Programmed or structured decisions involve well-defined, measurable and compatible criteria, while nonprogrammed or unstructured decisions come under the heading of "problem solving" (Simon 1977, p. 64-65). Operational decisions tend to be structured, while strategic decisions tend to be unstructured (Simon 1977). Based on this distinction we will use the following analytic framework to conduct the research study as presented in Table 1 .

Different decision types call for different methods of decision making and different information requirements (Gorry \& Scot, 1971). Techniques used for operational decisions, for instance, are rarely used in strategic decisions. In this study we focus on the distinction between operational versus strategic decisions as it relates to the use and type of BI used.

Table 1. Analytical framework

\begin{tabular}{|l|l|}
\hline Structured / Operational decisions & Unstructured / Strategic decisions \\
\hline $\begin{array}{l}\text { How is BI used in structured / } \\
\text { operational decision making? }\end{array}$ & $\begin{array}{l}\text { How is BI used in unstructured / strategic } \\
\text { decision making? }\end{array}$ \\
\hline $\begin{array}{l}\text { What kind of BI is used in structured } \\
\text { / operational decision making? }\end{array}$ & $\begin{array}{l}\text { What kind of BI is used in unstructured / } \\
\text { strategic decision making? }\end{array}$ \\
\hline
\end{tabular}

The purpose of this paper is to explore how decision-makers use BI in the context of different decision types based on the analytical framework illustrated in Table 1. In the next section, we describe the methodology used to investigate how decisionmakers use BI as a product, in terms of information, insights and knowledge in decision making.

\section{Research Design and Presentation of the Case Study}

The empirical basis for this research was an in-depth case study exploring the role of BI in decision making. We conducted an exploratory case study to provide insights into the use of different types of BI in different decision-making environments. Case studies are particularly valuable for exploratory research where a thorough understanding of a phenomenon in its context is preferred (Benbasat, Goldstein, \& Mead, 1987).

As an empirical setting we chose a financial institution in Scandinavia to explore how managers use BI in an organization with a strong tradition of using of hard data and financial models in forecasting activities.

\subsection{Research Setting}

The organization is an international financial institution with its headquarters in Scandinavia. The organization is recognized as a successful financial company with a 
high market share. The study was conducted in the IT unit, which is responsible for standardizing and automating processes, and developing IT systems to enhance the efficiency of the entire organization. The IT unit run by the chief information officer (CIO) and is composed of seven development areas managed by development directors. Each development area is further subdivided into departments headed by development managers. In total, there are 38 IT departments, employing 2200 employees.

\subsection{Data Collection}

We conducted eight interviews with key IT governance personnel in the case organization. Two additional interviews were conducted with external subject experts to triangulate the data. Background information about the company was also collected and served as complementary material to the interviews. The participants used BI in their everyday work and they were from different levels of the organization. The form of the interviews was semi-structured, with open-ended questions asked about the use of BI in decision makingAn interview guide was created before the interview that included questions such as:

- For what purposes do you use BI?

- Does the information in the reports support many decisions or does each report target a specific decision?

- How much do you believe BI influences your decisions?

- Do you base your decisions only on the numbers in the reports?

- Do you use other channels, methods, connections or tools to support your decisions?

Each interview was conducted at the interviewee's office and lasted an average of 60 minutes. Participants were informed that the interview was about the use of Business Intelligence in their decision-making activities, but were not shown the questions ahead of time. All the interviews were recorded with the consent of the interviewees. The interviews were carried out in English and were transcribed by the researcher afterwards. Table 2 presents the participants and their roles in the organization.

Table 2. Details of the interview participants

\begin{tabular}{|l|l|}
\hline Participant & Role in the organization \\
\hline Participant 1 & Head of IT Management Support \\
\hline Participant 2 & Head of IT Credit Processes \\
\hline Participant 3 & Regional Manager \\
\hline Participant 4 & Business Analyst \\
\hline Participant 5 & Head of Forecasting Models \\
\hline Participant 6 & Business Analyst \\
\hline Participant 7 & IT Finance Business Analyst \\
\hline Participant 8 & Performance Management Specialist \\
\hline Participant 9 & External expert on Project Portfolio Management \& BI \\
\hline Participant 10 & External expert on BI \\
\hline
\end{tabular}


The collected background material included organization charts, reports, spreadsheets, forms, PowerPoint presentations, memos, and meeting minutes. This documentation was collected in order to triangulate the data with the interviews.

\subsection{Data Analysis}

We carefully read through the transcripts of the interviews and the meetings as well as the official notes and the field notes to get a detailed picture of the empirical setting. While reading the interviews and meeting transcripts we were looking for indicators of how BI was used in decision-making processes. In order to investigate our research question, we employed constant comparative techniques (Strauss, \& Corbin, 2008) in which we gathered and analyzed qualitative data in a systematic and iterative manner.

During data analysis we applied open coding inspired by grounded theory (Strauss \& Corbin, 1998). Content analysis (Strauss \& Corbin, 1998) was also employed to assess the collected material. In particular, we read the documents and transcripts to identify themes in the raw data across the different sources. The themes pursued included concepts such as "reports", "hard facts", "scorecard", "performance", "data" and "decision". We organized these first order codes into tables that illustrated a single theme across the various data sources, inspired by the in-vivo coding technique (Strauss, \& Corbin, 2008). In the next step, we developed second order themes by using the four key questions of the framework to sort through the data. Those questions were: 1) How is BI used in unstructured strategic decisions? 2) How is BI used in structured operational decisions? 3) What type of BI is used in strategic decision making? 4) What type of $\mathrm{BI}$ is used in operational decision making? In the final step, through an iterative analysis of the data, "informing", "dialogue" and "convincing" and their relationship to "BI and decision making" emerged as transparently observable phenomena (Eisenhardt, 1989) in the data.

\section{Results}

In this section, we present how and in what forms $\mathrm{BI}$ is used in decision making in the following categories that emerged from the data analysis phase.

\subsection{The Use of $\mathrm{BI}$ in Decision Making}

Decision-makers use BI for different purposes in the decision-making process. We illustrate each purpose observed in our case in the next paragraphs, attaching representative quotes from the interview data.

\section{Using BI to Inform Decisions}

The interviewees reported that they use BI to directly inform their decisions. This is especially obvious when BI addresses specific or structured decisions, creating a tight linkage between intelligence and decisions. In this case, data are analyzed with a specific question in mind and the report adresses this specific question.

"So therefore, we need to ... come up with some good reporting on how we can allocate our capital in the best manner. So, where do we actually target the customer groups which we want to target and on what kind of product areas do we actually 
want to target in order to allocate our capital in the right way? So that's sort of the reporting we do, saying okay, we need this, we know that this customer group is very profitable and also have a potential long term relation with the company. So, we need to focus on this area and that's where we should allocate our capital and that would be a clear decision based on our reporting, saying okay, this is the target group that we need to focus on." (Participant 8)

"I think, what we learned was that the margins for instance regarding price need to be adapted to the new environment in the financial crisis. So that's something that came quite clear in the reporting that we did, meaning that each brand initiated various projects in order to sort of adopt the price level margins to current environment, so there you can see actually direct sort of decisions being based on the reporting." (Participant 6)

\section{Using BI as an Instrument for Dialogue}

When asked how BI influences their decisions, managers responded that they use the reports, scorecards and dashboards as an instrument for dialogue with other employees and departments in the organization and thus as the basis for further investigation.

"It is a dialogue tool, primarily because other factors are also in play, which are not captured by our scorecard. So, the scorecard is a foundation for measuring performance, no doubt about that, but other factors, I think we call them hygiene factors ... it could be other information that [the manager] is just extracting from the market, providing it to the management or all other things that are sort of intangible, that we cannot measure. So we don't believe that you can measure business purely by mathematical numbers and performance, you need to look it as a whole perspective that's why I mentioned it as a dialogue tool." (Participant 8)

"We use it both for ourselves correcting the accounts when it is wrong, but we also use this information to have a dialogue with the system owner..." (Participant 7)

"Well it creates a dialogue, it creates a conversation in the executive committee saying, do we actually have the right price focus on each sub-customer segment. And that creates a sort of decision-making process" (Participant 8)

$\mathrm{BI}$ is thus seen as a dialogue opener, allowing managers to engage in a discussion as they interpret the results and try to make sense of the numbers. According to the interviewees, there are other aspects not captured by BI. As indicated in the following quotes, BI is only part of the picture that initiates the dialogue. Tacit knowledge and experience also play a very important role in creating a full picture of the problem or issue discussed.

"I call the managers and ask them what do you do since you are doing so well and what is the problem since you are red in this area." (Participant 4)

"So, as I mentioned it, ... I think you need to have a dialogue. You need to have this human touch and you need to get a feeling also what's going on in the business. Also, lots of information is impossible for us to measure, so lots of information is coming, sort of, from discussions and that's also part of the decision-making process. So, I think, all the reporting that we do, all the ratios that we deliver, all the numbers are just a part of it and then the rest is based on your, I wouldn't say gut feeling, but your business knowledge and your conversations with the business, that is also a very important part of decision making." (Participant 8) 
"When you see the results or the data you should use your common sense, so when you make a decision you should sort of respect your data and the story, you should investigate: does it make sense?" (Participant 2)

\section{Using BI as a Convincing Argument}

The interviewees use data as a powerful tool to convince top management about the significance of an issue and its impact. Having data to support your argument legitimizes decisions, particularly in front of other people. In the following quotes one can observe how data are used to convince others in making a certain decision and taking action.

Interviewee: No, [the data] is just the argument, but very often if you want to have something in a hurry, then you need the data because it is the only way that you can convince people that this is a serious problem. You have to be able to tell to people, well this is affecting 100,000 customers, this is affecting all brands and you always have to tell how serious is this issue." (Participant 2)

"...well, we have been looking into your data for the last month. We really have some deviations here, you need to solve it and there we have the material, you know, you can present it to them saying, okay you can see it here, these are the dated deviations throughout the last 30 days." (Participant 7)

\subsection{Types of BI in Decision Making}

The mainstream BI used by the interviews consisted largely of reports and spreadsheet analysis of past historical performance data. However, the interviewees reported that more advanced analytics such as what-if scenarios are often more useful in strategic decision making.

\section{Standard Reporting of Past Performance}

The interviewees stated that they use the information from reports in structure / operational decisions where the steps to solve the problem are well defined. We provide examples here of how one of the managers uses BI in operational decision making.

"As I said, we need to close the books ... so I needed to go down to transaction level actually to see if those transactions ended up correctly in the accounting system, so that was the main purpose..." (Participant 7)

"So, BI tools are used ... rather for investigations in connection with testing activities or tracing errors, alright? So I'm not using BI for making decisions if we need to man up by one FTE [full time employee] or see if I should get rid of one FTE and which one or whatever could be a part of my decision making as a department head, right?" (Participant 7)

\section{Predictive Analytics}

The use of what-if scenarios along with correlations between events and their implications can provide a sound foundation for decision making. This type of BI falls into predictive analytics and is particularly important for strategic decisions. 
Predictive analytics are used to create a variety of what-if scenarios in order to predict future outcomes through forecasting and deep data analysis.

"At the end of the day, it is a business decision which projects you would like to support. So, you can never automate, but what makes sense is actually not to create the portfolio but when you need to make changes in the portfolio if you take the resources into scope, the bottlenecks, the limitations into scope, then you can use it for a kind of decision base. But it is really more to have a foundation for an enlightened decision ... you can never use it mechanically, it would never work. But you can say the consequence of doing this is $X$ and the consequence of doing this is $Y$. But I think the effect is indirect." (Participant 9)

\section{Discussion and Conclusion}

The results presented in the previous section show how BI directly informs structured decisions. BI may also inform partially tactical and strategic decision making when it addresses the specific decision. However, when BI addresses a range of different decisions it is primarily used as an instrument for dialogue or as a convincing tool in tactical and strategic decision making.

BI extracted by standard reporting, including scorecards and dashboards, addresses a range of different decisions. This limits its use in tactical and strategic decision making because the information extracted does not address a specific decision but rather generates questions in an effort to illuminate multiple decisions. Organizations face a trade-off between providing BI for decision-specific support and providing BI for a variety of decisions. Decision-specific support requires considerable organizational effort and capital. At the same time, providing BI for a range of different decisions does not necessarily assure adequate support of the individual decisions. Davenport (2010), considering the above trade-off, suggests that companies should select the most important organizational decisions and create the appropriate BI support.

BI also appears as an instrument for dialogue in decision making. While the information or knowledge extracted does not address specific decisions, it can help managers to engage in dialogue to make sense of information and to investigate options. Decision-makers often need to tackle tactical and strategic decisions in which the decision criteria are not well defined or measurable. In this case, information or knowledge extracted is only part of the picture and managers need to engage in a dialogue in order to consider and discuss "the rest of the truth" that is not captured in reports. As the interviewees stated, the dialogues iniated by BI often bring up contextual and business knowledge as part of the discussion. Choo (1998) refers to this use of information as "enlightenment" in which "information is used to develop a context or to make sense of a situation."

$\mathrm{BI}$ is premised on the rational-scientific paradigm that there is an objective truth that can be measured. We found that BI is often positioned as "hard facts" and is used by decision-makers as an argument to support or justify their decisions and to convince others. However, using BI as a convincing argument could have some negative implications for organizations. For example, according to March (1995, pp.), "numbers presuppose a concept of what should be measured and a way of translating 
that concept into things that can be measured". He continues by positioning "...the pursuit of truth as a sham..." in which "decision-makers find it possible to "discover" a truth that happens to be consistent with their own interests." In this view, data provides knowledge, knowledge is power and, therefore, data is power. In organizations in which evidence is required to legitimize decisions, the power of hard facts increases, as does the likelihood that managers will "find" hard facts that confirm their beliefs. This behavior is similar to a decision-based evidence making approach (Tingling, \& Brydon, 2010).

Our results show that information extracted from reports, scorecards and dashboards largely addresses and informs structured, operational decisions. This finding is consistent with the results of Isik et al. (2010) who found that data-oriented BI capabilities are more critical for operational decisions than for strategic decisions. As we move from structured to unstructured decisions, the use of BI in decision making changes from informing decisions to serving as an instrument for dialogue. The use of BI as a dialogue tool initiates conversations that, according to May (2009), have a positive impact on organizational performance because they stimulate learning.

The impact of using BI as a dialogue tool in decision making is indirect. Although it does not directly support or inform decisions, it creates a context in which decisionmakers can interpret the information and discuss the problem. Predictive analytics, techniques that exploit patterns found in historical data to identify risks and opportunities, appear to be especially useful in this case. These techniques capture relationships among many factors and allow the development of different possible scenarios in decision making. With predictive analytics, the range of situations in which BI can be used expands considerably, especially in strategic decision-making. On the other hand, we observe that BI extracted by standard reporting, including scorecards and dashboards, is generally used in operational decision making. Their actual use in strategic decisions is limited because of their reactive nature.

The contribution of this paper is twofold. First, our findings illustrate the role of BI in strategic decision-making environments. These findings suggest that BI as a product - information, insight or knowledge - is used to foster dialogue or as a convincing instrument in strategic decision making, but appears to have a more direct impact in operational decision making because it informs specific decisions. Second, we have found that BI standard reporting capabilities that analyze past performance are useful for structured, operational decisions, while predictive analytics that focus on modeling to create competitive advantages are more useful in unstructured, strategic decision making.

This study has several implications for research and practice. From a research standpoint, our study explores the role of BI in decision making as an instrument for dialogue that engages managers in interpretation and knowledge externalization. This use of BI as an instrument for dialogue indicates new perspectives for IS researchers, suggesting that we address BI not as mere facts but as a sensemaking mechanism in decision making. From the point of view of practice, the study has implications for designing and developing BI decision support infrastructures. Organizations should consider the right type of $\mathrm{BI}$ according to the nature of the decision and should be aware of the degree to which evidence is required in legitimizing decisions in order to avoid evidence making by decision-makers. To provide adequate support for each type of decision-making environment, we need further studies of the relationship 
between the use of BI in both strategic and operational decision-making environments. We propose these as possible future research streams.

The purpose of this paper has been to explore the role of BI in decision making. We have reported findings from an empirical study in which managers from a large organization were interviewed in relation to their BI-use in decision making. We have argued that $\mathrm{BI}$ is used as a dialogue and convincing instrument in strategic decision making, and have introduced new theoretical insights into BI research.

Acknowledgments. The author wishes to express her gratitude to her supervisor, Professor Karlheinz Kautz and Associate Professor Ioanna Constantiou who offered invaluable assistance, support and guidance. Special thanks also to her friends and Ph.D. students Konstantinos Manikas and Maria Ie Pedersen for invaluable reviewing assistance.

\section{References}

Arnott, D., Pervan, G.: Eight Key Issues for the Decision Support Systems Discipline. Decision Support Systems 44(3), 657-672 (2008)

Blumberg, R., Atre, S.: The Problem with Unstructured Data. DM Review Magazine (2003)

Baars, H., Kemper, H.-G.: Management Support with Structured and Unstructured Data - an Integrated Business Intelligence Framework. Information Systems Management 25(2), 132 148 (2008)

Benbasat, I., Goldstein, D.K., Mead, M.: The case research strategy in studies of information systems. MIS Quarterly 11, 369-386 (1987)

Chaudhury, S., Dayal, U.: An Overview of Data Warehousing and OLAP Technology. ACM SIGMOD Record 26(1), 65-74 (1997)

Choo, W.C.: The Knowing Organisation: How Organisations Use Information to Construct Meaning, Create Knowledge, and Make Decisions. Oxford University Press, Oxford (1998)

Chung, W., Hsinchun, C., Nunamaker Jr., J.F.: A Visual Framework for Knowledge Discovery on the Web: An Empirical Study of Business Intelligence Exploration. Journal of Management Information Systems 21(4), 57-84 (2005)

Clark, T.D., Jones, M.C., Armstrong, C.: The Dynamic Structure of Management Support Systems: Theory Development, Research Focus and Direction. MIS Querterly 31(3), 579615 (2007)

Davenport, T.H.: Competing on Analytics. Harvard Business Review 84(1), 98-107 (2006)

Davenport, T.H.: Bi and Organisational Decissions. International Journal of Business Intelligence Research 1(1), 1-12 (2010)

Davenport, T.H., Prusak, L.: Working Knowledge: How Do Organisations Manage What They Know. Harvard Business School Press, Boston (1998)

Dekkers, J.V., Johan, Batenburg, R.: Organising for Business Intelligence: A Framework for Aligning the Use and Development of Information. In: BLED 2007 (2007)

Dybå, T., Dingsøyr, T.: Empirical Studies of Agile Software Development: A Systematic Review. Information and Software Technology 50(9), 833-859 (2008)

Eisenhardt Strauss, A., Corbin, J.: Basics of qualitative research: Grounded theory procedures and techniques, 3rd edn. Sage Publictions, Newbury Park (2008) 
Fowler, A.: The Role of Ai-Based Technology in Support of the Knowledge Management Value Activity Cycle. The Journal of Strategic Information Systems 9(2-3), 107-128 (2000)

Fuld, L.: Be Prepared. Harvard Business Review 81(11), 20-21 (2003)

Golfarelli, M., Stefano, R., Iuris, C.: Beyond Data Warehousing: What's Next in Business Intelligence? In: Proceedings of the 7th ACM international workshop on Data warehousing and OLAP. ACM, Washington, DC, USA (2004)

Google Ngram Viewer (2011), http://ngrams.googlelabs.com/

Gorry, G.A., Scott, M.M.S.: A Framework for Management Information Systems. Sloan Management Review 13(1), 55-72 (1971)

Gray J., Bosworth A., Layman A., Pirabesh H.: Data cube: a relational aggregation operator generalizing groupby, cross-tab, and sub-totals. Microsoft Technical Report (1996)

Hostmann, M., Reichert, P., Borsuk, M., Schweizer, S., Spörri, C., Tockner, K., Truffer, B.: Concepts of decision support for river rehabilitation. Environmental Modelling and Software 22, 188-201 (2007)

Inmon, W.H.: Building the Data Warehouse, 4th edn. Wiley, Indianapolis (2005)

Isik, O., Jones, M., Sidorova, A.: Business Intelligence Success: An Empirical Evaluation of the Role of BI Capabilities and the Decision Environment. In: Proceedings of the SIGDSS/TUN, Business Intelligence Congress II, Saint Louis, MI, USA (2010)

Kimball, R., Ross, M.: The Data Warehouse Toolkit, 2nd edn. John Wiley \& Sons, Chichester (2002)

Kinsinger, P.C.: The Business Intelligence Challenge in the Context of Regional Risk. Thunderbird International Business Review 49(4), 535-541 (2007)

Luhn, H.P.: A Business Intelligence System. IBM Journal (1958)

March, G.J.: A Premier in Decision Making: How decisions happen, 1st edn. Free Press, New York (1995)

Martinsons, M.G.: A Strategic Vision for Managing Business Intelligence. Information Strategy: The Executive's Journal 10(3), 17 (1994)

May, T.: The New Know: Innovation Powered by Analytics. Wiley \& Sons, New Jersey (2009)

Negash, S.: Business Intelligence. Communications of AIS 13, 177-195 (2004)

Presthus, W., Brevik, E.: E-business in entertainment: Insights from the use of Business Intelligence in the Norwegian music industry. In: Proceedings of AMCIS 2010, Paper 40 (2010)

Rockart, J., De Long, D.: Executive Support Systems. Dow Jones-Irwin, Homewood (1988)

Simon, H.A.: The New Science of Management Decision, 3rd revised edn., 1st edn. 1960. Prentice-Hall, Englewood Cliffs (1977)

Shariat, M., Hightower, J.R.: Conceptualizing Business Intelligence Architecture. Marketing Management Journal 17(2), 40-46 (2007)

Shollo A., Kautz K.: Towards an Understanding of Business Intelligence. In: Australasian Conference on Information Systems, Brisbane, Qeensland (2010)

Sprague, R.H.: A Framework for the Development of Decision Support Systems. MIS Quartely 4(4), 1-26 (1980)

Steiger, D.: Decision Support as Knowledge Creation: A Business Intelligence Design Theory. International Journal of Business Intelligence Research (IJBIR) 1(1), 29-47 (2010)

Strauss, A., Corbin, J.: Basics of qualitative research: Grounded theory procedures and techniques, 3rd edn. Sage Publictions, Newbury Park (2008) 
Tzu, S.: The art of war. Filiquarian Publications, LLC (2006)

Tingling, P.M., Brydon, M.J.: Is Decision-based Evidence Making necessarily bad? MIT Sloan Management Review 51(4), 71-76 (2010)

Webster, J., Watson, R.T.: Analyzing the Past to Prepare for the Future: Writing a Literature Review. MIS Quarterly 26(2), 13-23 (2002)

Wixom, B., Watson, H.: The BI-Based Organisation. International Journal of Business Intelligence Research (IJBIR) 1(1), 13-28 (2010)

Yi-Ming, T., Liang-Cheng, C.: Dynamic Interactive Framework to Link Business Intelligence with Strategy. International Journal of Information Technology \& Management 6(1), 2 (2007) 